\title{
LA MONSTRUOSIDAD Y EL SIGNO: FORMAS DE LA PRESIGNIFICACIÓN EN EL RENACIMIENTO Y LA REFORMA*
}

\author{
María José Vega Ramos
}

Universidad Autónoma de Barcelona

\section{PRESIGNIFICACIÓN: MONSTRUOS, PORTENTOS, PRODIGIOS}

Los sucesos que se producen contra natura se llaman monstra, ostenta, portenta, prodigia: San Agustín, en el De civitate Dei, precisa que se les nombra monstra, de monstrare, porque muestran alguna cosa, a la que significan; se llaman ostenta, de ostendere, portenta, de portendere, y prodigia porque dicen en la lejanía (porro dicere), esto es, porque predicen las cosas futuras ( $\mathrm{De}$ Civ. Dei, XXI.8). Los monstruos, prodigios y portentos son medios por los que Dios manifiesta su presencia y su poder:

* Con mi agradecimiento a la Herzog August Bibliothek de Wolfenbüttel y a la Institución Cultural el Brocense de Cáceres. 
Nobis tamen ista, quae... monstra, ostenta, portenta, prodigia nuncupantur, hoc monstrare debent, hoc ostendere vel praeostendere, hoc praedicere, quod facturus sit Deus, quae de corporibus hominum se praenuntiavit esse facturum, nulla impediente difficultate, nulla praescribente lege naturae (De Civ. Dei, XXI.9).

Cicerón, en el De divinatione (I.42.93) y en el De Natura Deorum (II.3.7), había propuesto ya las mismas etimologías, con observaciones semejantes, que son las que posteriormente se reencuentran, sin variaciones de sustancia, en el libro undécimo de las Etymologiae de San Isidoro:

Monstra vero a monitu dicta, quod aliquid significandum demonstrent, sive quod statim monstrent quid appareat, et hoc proprietatis est; abusione tamen scriptorum plerumque corrumpitur. Quaedam autem portentorum creationes, in significationibus futuris constitutae videntur. Vult enim Deus interdum ventura significare per aliqua nascentium noxia, sicut per somnos, et per oracula, quibus praemoneat et significet quibusdam vel gentibus, vel hominibus futuram cladem, quod plurimis etiam experimentis probatum est (Etym. XI.3).

Existe un grupo nutrido de términos latinos de la presignificación y de sus formas: además de praesensio y de los verbos praesignificare y praenuntiare, incluye los sustantivos que la tradición etimológica relaciona con la mostración y la ostensión, esto es, los monstruos, ostenta, portentos y prodigios. El ámbito de la presignificación, es, en general, y en sentido estricto, el de la larga tradición occidental de las artes divinatorias, pero penetra igualmente el discurso de la historia y la filosofía naturales, de la cosmografía, de la cronografía y de la historia mundi, así como el de las misceláneas y el de la literatura didáctica.

Hay varias implicaciones relevantes en la consideración del progidio y de la monstruosidad como instancias de presignificación: en primer lugar, el prodigio y el monstruo se constituyen en significantes de un significado diferido o demorado, ausente en el momento de su aparición o de su nacimiento. En esto, se asemejan a los textos proféticos, que postulan una referencia diferida y que se presume «ausente» en el momento de la escritura. Por otra parte, sin embargo, los monstruos y los prodigios no son textos (aunque, como se verá, se comportan como textos) y requieren una estrategia interpretativa diversa. Al igual que las profecías, los monstruos y los prodigios suelen leerse como una alusión al presente del exégeta, y requieren una correlación de interpretaciones, la del monstruo o el texto y la de los hechos, que se refuerzan y 
legitiman mutuamente. Como ellas también, los monstruos y prodigios suelen ser vaticinios ex eventu (posteriores a los hechos que presuntamente profetizan) o bien objeto de interpretaciones post factum; su descripción y difusión es también posterior a la de los hechos que anuncian o pre-significan, y suelen ser utilizados - descritos, interpretados, publicados - con fines políticos y religiosos. Ahora bien, mientras que las profecías pueden ser divinas (o reveladas) o alcanzadas por los hombres doctos, los prodigios son, en todos los casos, una forma de la manifestación de la voluntad de Dios, more allegorico, a todos los hombres.

Este artículo versa sobre los monstruos y prodigios entendidos como signos y como praesensiones o nuncios, y, más particularmente, se circunscribe a los años en los que florecieron las compilaciones de hechos portentosos, los tratados y las historias de la monstruosidad y las vastas crónicas de los prodigios acaecidos desde la creación del mundo. A pesar de estas restricciones, las ramificaciones de esta materia son muy notables y no podrán ser exploradas aquí en su totalidad: los monstruos y prodigios comparecen en varias disciplinas tradicionales, se imbrican con la situación política y religiosa del momento de su aparición, son objeto de la especulación historiográfica y cronológica, y están relacionados tanto con la filosofía natural como con la exégesis escrituraria.

\section{TRES TIPOS DE TEXTOS: BREVE EXCURSO BIBLIOGRÁFICO}

El siglo XVI asiste a la proliferación de los libros de prodigios, catálogos de portentos, historias de la monstruosidad y cronologías de hechos prodigiosos. El número de textos y la frecuencia de sus reimpresiones evidencian la singularidad de este fenómeno. No es éste el lugar apropiado para avanzar las causas posibles de este renovado interés por los hechos portentosos e insólitos, que es, en otros términos, un interés por las formas de la presignificación y por el seguimiento de las manifestaciones de la voluntad divina. Baste decir que ni los tipos de textos ni los modos de interpretación carecen de antecedentes clásicos: es notable, sin embargo, la creencia en la profusión y multiplicación de los hechos prodigiosos, y la abundancia de los libros que los relatan, de las hojas sueltas que los reproducen y explican y de los pan- 
fletos que las recogen. Antes de abordar los mecanismos de la praesensio, es procedente señalar cuáles son los tipos de textos, qué historias catalogan e interpretan los signos prodigiosos, puesto que de esta tipología se siguen algunos corolarios relevantes para la comprensión del fenómeno de la presignificación.

La publicación de los libros de prodigios es especialmente notable, en cantidad y calidad, en el siglo XVI y a comienzos del siglo XVII, y, más particularmente aún, en los cincuenta años que median entre 1520 y 1570 . Entre los años 1550 y 1563 aparecen los textos más prolijos, exhaustivos y relevantes, ya que su influencia se extiende a todas las obras publicadas con posterioridad. Las áreas geográficas en las que se produce una concentración significativa de textos sobre el prodigio son las de influencia germánica: es más significativo aún que los autores de las obras más importantes pertenezcan al ámbito evangelista, sean promotores activos de la reforma, estén en contacto con el círculo de Wittenberg, o, en general, puedan adscribirse a las tesis luteranas. De hecho, el catálogo más extenso y exhaustivo, el Prodigiorum ac Ostentorum Chronicon de Conrado Lycosthenes, fue condenado por la Iglesia católica e incluido en el índice de libros prohibidos dos años después de su publicación, y no hay que olvidar que Lutero y Melanchthon son autores de un libellus, publicado en 1523, dedicado íntegramente a interpretar el significado de dos seres monstruosos y contra natura. Para obviar aquí una larga relación de los textos publicados en las décadas áureas de los prodigiorum libri en los que se basan estas páginas, se ha dispuesto la relación cronológica de los más relevantes en la Tabula $I$.

1531: P. Vergilius, De prodigiis

1532: Camerarius, De Ostentis

1532: F. Nausea, Liber Mirabilium

1552: Obsequens-Lycosthenes, Prodigiorum Liber

1553: Peucerus, Teratoscopia

1555: Frytschius, Catalogus Prodigiorum (I)

1556: Fincelius, Wunderzeichen (I)

1557: Lycosthenes, Prodigiorum ac ostentorum Chronicon

1557: Goltwurm, Wunderzeichen

1559: Fincelius, Wunderzeichen (II)

1560: Boaistuau, Histoires Prodigieuses

1561: A. Paré, Des Monstres et Prodiges

1562: Fincelius, Wunderzeichen (III).

1563: Frytschius, Catalogus Prodigiorum (II) 
1570: Sorbinus, Tractatus de monstris

1575: C. Gemma, Cosmocritica

1585: M. C. Irenaeus, De monstris

1591: A. Dubenus, Catalogus Prodigiorum

1595: Weinrichius, De ortu monstrorum

1595: J. Colerus, Wunderwercken

1597: A. Angelus, Wunderbuch

1600-1662: C. Bauhinus, J. Landray, J-G Schenccius, J. Riolan, F. Licetus, J. Jonstonius, U. Aldrovandus, Stengelius, C. Schottus.

Este conjunto de textos, con ser homogéneo en cuanto al tipo de información, presenta algunas diferencias relevantes en la aproximación al signo prodigioso. Hay, al menos, tres grandes grupos que he designado con los términos más utilizados en el siglo XVI: teratoscopia, catalogum o chronicon, y thaumatographia o historia monstrorum. Los tres difieren tanto en los matices introducidos en la aproximación al fenómeno como en el «género» y en la disposición del texto.

\section{Teratoscopia}

La teratoscopia designa la rama de las artes divinatorias que se basa en la interpetación del prodigio y el monstruo: el término está acuñado a partir de la raíz téras, que designa, a la vez, un ser monstruoso y un signo. Casparus Peucerus es el responsable de su generalización en el siglo XVI al escogerlo para titular una de las partes principales de su Commentarius de praecipuis divinationum generibus, que es uno de los tratados de adivinación más difundidos en el ámbito protestante. De hecho, la teratoscopia quinientista está asociada indisolublemente a la información proporcionada por Peucerus. Esta forma de la adivinación especula sobre el valor del prodigio y el monstruo como signo o heraldo de las cosas futuras tanto en un plano general como en el particular: esto es, indaga, en lo particular, las relaciones de cada prodigio y monstruo singular con los hechos también singulares que pre-significan o anuncian de forma analógica o alegórica y, en general, postula la participación divina e identifica la causa última de los hechos prodigiosos en la voluntad divina de pre-significar. En palabras de Peucerus: los monstruos y prodigios son testimonios divinos, son signa que han de ser rectamente interpretados, y que poseen una significatio a pesar de que ésta apenas pueda ser percibida por el hombre (1553: $9 \mathrm{r}^{\circ}$ ); cuando se ofuscó la sapiencia divina con el pecado original, el hombre 
comenzó a percibir la naturaleza como a través de nubes densas («rerum paucarum causas pernoscimus, ideoque de effectis non dextre ratiocinantur. Signa vero paucissima assequimur, aut de eventibus illis interpretamur quos revera denotant» [ibid.]). Si toda adivinación (praesensio et scientia rerum futurarum) implica la interpretación de signos, la teratoscopia, que es una de sus ramas, es la interpretación de los monstruos, portentos y ostentos en tanto que son signos que pre-significan hechos futuros (Peucer, 1553: $\left.442 \mathrm{v}^{\circ}\right)^{1}$.

\section{Catalogum}

El segundo grupo está formado por las crónicas y catálogos de prodigios ordenados cronológicamente desde el principio del mundo hasta el presente del compilador. El modelo clásico es un texto fragmentario de un historiador latino, el enigmático Julius Obsequens, conocido por el título de Prodigiorum Liber. Esta obra fue editada (y completada) por el enciclopista suizo Conrado Lycosthenes, y obtuvo un notable éxito (amén de ser objeto de traducciones a lenguas vulgares). Los modelos recentiores proporcionan la estructura general de la obra y su fundamento cronográfico: estos modelos son los estudios y publicaciones de los cronógrafos protestantes, como la Supputatio de Lutero y la vastísima cronología del mundo de Funccius, de los que se toman los cómputos cronográficos, la determinación de las eras y los argumentos escatológicos obtenidos de la especulación sobre las edades del mundo.

Los catálogos comprenden una colección de descripciones de prodigios y monstruos acompañadas, por lo general, de una interpretación doctrinal del fenómeno portentoso o de la sucinta enunciación de los hechos históricos que predijeron. Sus noticias proceden de una multitud de fuentes, ya que los catálogos de prodigios forman una serie acumulativa, de modo que cada nuevo libro recoge las maravillas relacionadas por los anteriores y añade otras nuevas. Los prodigios antiguos están recabados de las escrituras, de los textos de historiadores latinos y cristianos, de los libros de historia natural; los modernos portentos, de las crónicas particulares, de los textos sobre adivinación, de panfletos y hojas sueltas, de almanaques y prácticas. Aunque suelen carecer de declaraciones programáticas, los casos descritos e interpretados permiten colegir que comparten la tesis teratocópica de que los fenó-

1 Ha de señalarse, no obstante, que, especialmente en el caso de los fenómenos celestes, Peucerus discrimina la semantica (sic) de los elementos no significativos (asemanta). 
menos maravillosos son nuncios de sucesos futuros, y, particularmente, de calamidades inminentes, que son manifestaciones de la ira divina o advertencias de Dios a los hombres, o bien signos de la proximidad del fin de los tiempos y de la segunda venida de Cristo.

El texto más relevante de este grupo es la copiosa crónica de Lycosthenes, el Prodigiorum ac ostentorum Chronicon, que apareció en 1557. Las noticias allegadas por Lycosthenes reaparecen en las crónicas posteriores, tanto latinas como alemanas, y tuvieron una notabilísima difusión en enciclopedias, como los Dies caniculares, en colecciones de relatos prodigiosos, como las Histoires de Boaistuau, en obras historiográficas, como las Lectiones Memorabiles de Johannes Wolf, en obras médicas y de historia natural, en panfletos y pagellae. De las muchas virtudes de este volumen hay una especialmente destacable: la de realizar una historia de la presignificación mediante monstruos y portentos y la de evidenciar cuáles son los períodos de la historia en la que se ha producido una proliferación y multiplicación de los signos divinos. Esto es, permite, por acumulación de casos particulares, aproximarse a una primera sistematización del código oculto de la divinidad.

\section{Thaumatographia}

El término thaumatographia, si bien comparece en el siglo XVI, no parece generalizarse hasta el siglo XVII y designa la descripción de lo maravilloso, insólito y portentoso. Como taumatógrafo se identifica Jonstonius, en la vastísima Thaumatographia Naturalis. Se entiende por taumatografía la aproximación a lo maravilloso desde el punto de vista de la física y la historia natural: esto es, la destinada a la descripción y clasificación de los fenómenos maravillosos e insólitos y al hallazgo de sus causas. En general, este tipo de descripción suele excluir ( $y$, en ocasiones, niega explícitamente) la consideración de lo prodigioso como un signo alegórico o profético de la divinidad. Antes bien, se alinea con las tesis aristotélicas expuestas en los libros de animalibus, en los que los monstruos se definen como errores de la naturaleza o errata Naturae. Los monstruos y prodigios, por tanto, son hechos que deben explicarse a partir de los mecanismos de la naturaleza misma que los produce o como efectos perversos o aberrantes. Aunque pueden hallarse argumentos conciliatorios de la aproximación taumatográfica (que entiende el prodigio como efecto) y la teratoscópica (que entiende el prodigio como signo), la adopción de los princi- 
pios aristotélicos suele ser incompatible con la lectura divinatoria. Esto es: la taumatografía indaga el prodigio retrospectivamente, frente a la indagación prospectiva de la teratoscopia; el efecto sustituye al signo, el pasado al futuro, la naturaleza a la divinidad. A la tradición taumatográfica responde el proyecto de la historia de las maravillas y prodigios, o de la naturaleza que yerra y que varía, que Sir Francis Bacon diseña en su Novum Organum como complemento de la historia natural (o naturaleza que sigue su curso), y frente a los excesos de los prodigiastri y de los mirabilaries, es decir, de los autores de catálogos y artes divinatorias.

Estos tres grupos, la teratoscopia, la crónica y la taumatografía, no incluyen aquellos textos en los que las maravillas y los prodigios no son el tema principal y dominante, como las enciclopedias que, entre otras materias, describen e interpretan fenómenos maravillosos, las cosmografías y crónicas de viajeros que, ocasionalmente, incluyen prodigios y portentos o recogen y reescriben los pasajes plinianos sobre las razas monstruosas de la periferia del mundo. Los tres grupos de libros dedicados específicamente a lo maravilloso evidencian que son varias las disciplinas implicadas en la aproximación a este fenómeno: la historia y filosofía natural, la cronografía y la historia, la exégesis escrituraria, y las artes adivinatorias. Aquí interesa, de este rico material, el conjunto de textos que se aproxima al monstruo y al portento como signa o como praesensiones. Las formas de interpretación de estos fenómenos pueden esclarecerse ulteriormente mediante la descripción de dos casos particulares.

\section{DOS CASOS EJEMPLARES: EL NIÑO DE FRANCONIA Y EL GALLO DE ALSACIA}

En 1546 nace en Franconia un niño con un cuchillo en el vientre. Este caso aparece recogido y descrito por varios autores quinientistas de crónicas y teratoscopias con una interpretación coincidente: esto es, como un signo cierto de la inminencia de guerras y desórdenes civiles (e.g., Frytschius, 1555, s.a. 1546; Lycosthenes, 1557, s.a., 1546; Gemma, 174-175). La Figura 1 reproduce la ilustración que acompaña la sucinta exposición del Prodigiorum ac Ostentorum Chronicon de Conradus Lycosthenes. 


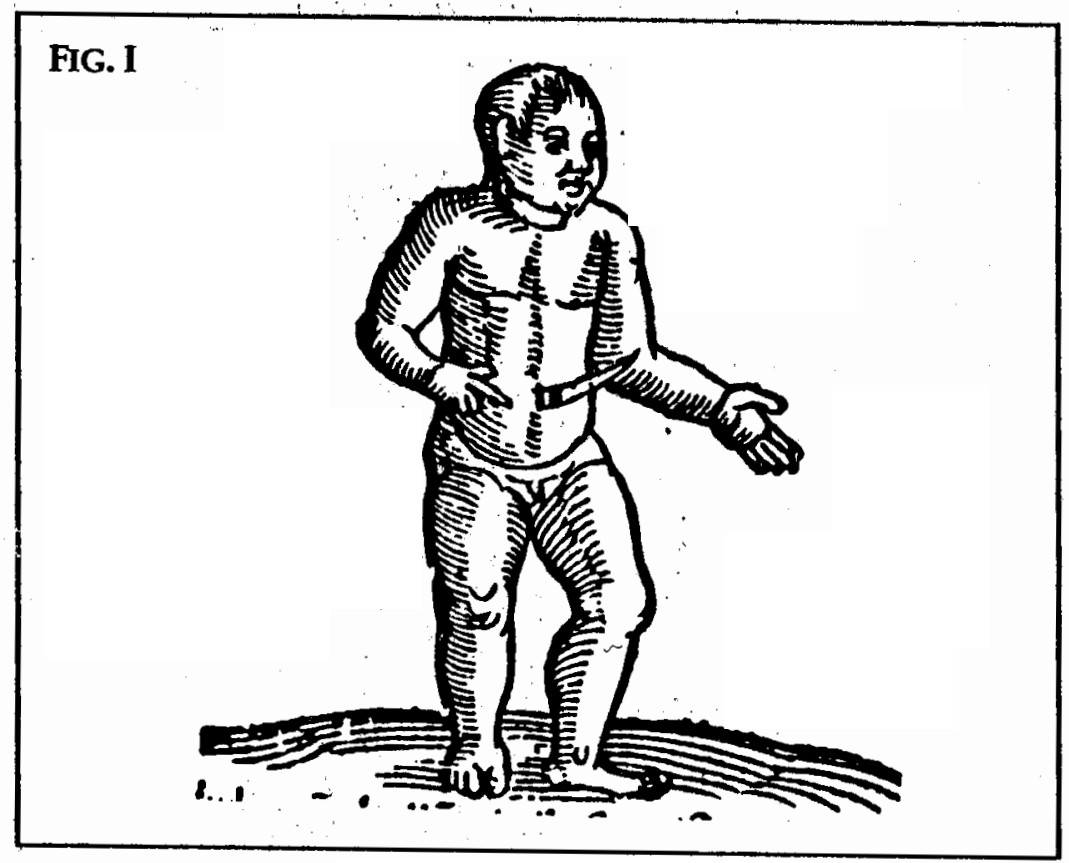

La significación del fenómeno se extrae al leer el cuerpo como metáfora del estado (lo cual es una lectura común de la monstruosidad); el arma, por sinécdoque, representa la guerra; el vientre, por analogía, y también por sinonimia, que la guerra será civil o intestina (intestina bella). Esta interpretación propone una lectura retórica del prodigio, que se decodifica como una alegoría compleja o como un tropo viviente, y es también una interpretación post factum, ya que postula una profecía cuya veracidad es fácil de corroborar una vez que se han producido los hechos presuntamente profetizados, a saber, las guerras de religión que culminaron en 1547 con la prisión del Elector de Sajonia por parte de Carlos V ${ }^{2}$.

Un caso diverso es el de la interpretación concedida a uno de los prodigios sucedidos en Alsacia. El 18 de abril de 1538, festividad de Jueves Santo, nació un gallo doble en una aldea alsaciana (vid. Figura II).

2 «... cui exemplo ex alvo matris culter iacuit in ventre, eminens cuspide extra ventrem, qui \& paulatim facta supputatione extractus est. Omnes indicarunt bellum civile significari, mutuasque civium inter se caedes, qui velut in viscera sua ferrum postea strinxerunt» (Frytschius, 1555, s. a. 1546). 


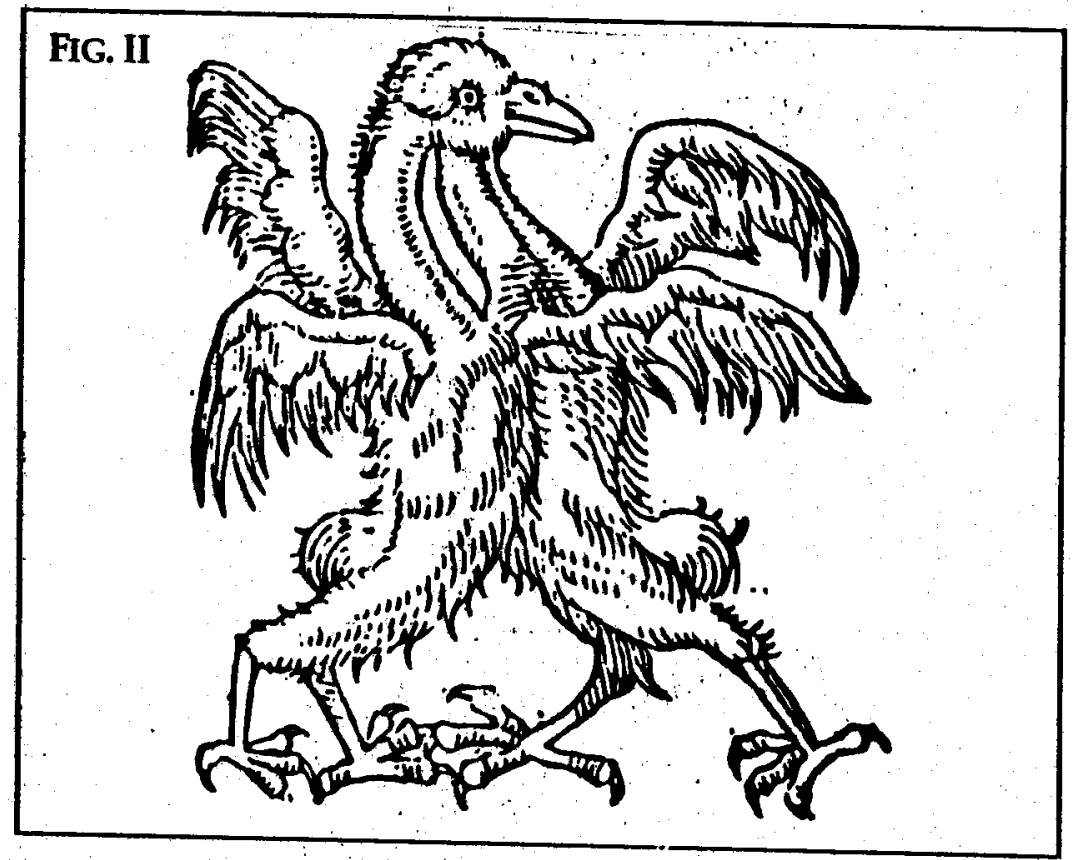

El pollo tenía cuatro alas, cuatro patas y una cabeza única y el día de su nacimiento fue el de la conmemoración de la última cena. El momento en el que se produce el fenómeno induce a interpretarlo como una manifestación divina sobre la verdadera naturaleza del sacramento: el gallo tiene una sola cabeza, y del mismo modo, en la comunión, los fieles se unen en un cuerpo con Cristo que es la única cabeza de la Iglesia. Las cuatro patas significan el acuerdo de los cuatro evangelistas al narrar la cena del Señor, narración que es, por tanto, la que debe seguirse como verdadera. El gallo representa, en su conjunto, la congregación de los fieles, que se apoya en el relato de los evangelistas (i.e., sola Scriptura) y no en otra autoridad, ley o tradición, y que reconoce una sola cabeza (Cristo) y no dos (Cristo y el papado).

La interpetación del pollo doble de Alsacia es puramente doctrinal: el momento de la aparición del prodigio es tan relevante como su apariencia para el establecimiento de su significado. La interpretación incide en cuestiones muy relevantes y conflictivas de la doctrina luterana: la administración de la comunión bajo dos especies, la autoridad única de la Escritura (frente a las normas eclesiales) y la afirmación de 
que Cristo y no el Papa es la cabeza que rige la Iglesia. Como en el ejemplo anterior, el cuerpo es una representación de la Iglesia o el Estado, y los miembros equivalen a otras tantas partes. En este caso, sin embargo, el prodigio no es profético, sino doctrinal: Dios se manifiesta a los hombres, a través de lo maravilloso, para entrar en la disputa del luteranismo con la Iglesia de Roma y manifestar su predilección por las doctrinas reformistas. Dios subraya su propia palabra: lo que está en las Escrituras se repite, alegóricamente, a través del prodigio. La Escritura y la maravilla, por tanto, siempre han de ser concordantes, pues tienen una única fuente: Dios mismo.

\section{SIGNOS MONSTRUOSOS: EL LENGUAJE DE LA DIVINIDAD}

El hecho de que la monstruosidad y los prodigios sean la forma elegida por Dios para comunicarse «directamente» con los fieles, sin la mediación de las jerarquías eclesiásticas, es quizá la premisa más relevante de este tipo de interpretación. Dios habla a través de la monstruosidad: o, en otros términos, el monstruo es la manifestación singular de la voluntad de pre-significar de Dios. El prodigio es el lenguaje escogido por la divinidad para comunicarse con los hombres, y ese lenguaje adopta la forma de emblemas vivos o representaciones analógicas que deben ser cuidadosamente interpetados ${ }^{3}$. En algunos casos, los monstruos pueden poseer también, como los emblemas, un texto: las palabras de advertencia que, en ocasiones, pronuncian antes de morir.

En cualquier caso, de la interpretación del monstruo y del prodigio como signos se siguen algunas observaciones. En primer lugar, que la monstruosidad y el prodigio parecen alzarse, en algunos textos quinientistas, a un nivel próximo al de la Escritura: son, como ella, manifestaciones divinas que requieren ser descifradas y cuya interpretación se sustenta, ocasionalmente, en evidencias escriturarias. La monstruosidad puede interpretarse no sólo mediante lecturas analógicas y trópicas, sino también, en ocasiones, a partir de la Escritura: como ella, además, admite varios niveles de sentido esto es, el literal, el alegórico

3 La condición emblemática de la maravilla y la monstruosidad se ve confirmada por el hecho de que los prodigios compilados en los textos del siglo XVI reaparecen en algunos libros de emblemas del siglo XVII con fines moralizantes. 
y el moral, ya que Dios, que se expresó en la Escritura y mediante la revelación, se manifiesta ahora en la monstruosidad y en la maravilla.

No obstante, junto a la lectura inspirada en la exégesis escrituraria (i.e., con niveles literales y alegóricos de sentido corroborados por pasajes paralelos de ambos Testamentos) o, más exactamente, de forma simultánea, el monstruo y el prodigio se leen de forma retórica, como tropos complejos y vivientes. En algunos casos, pueden segregarse estas dos aproximaciones interpretativas: si el caso del niño de Franconia es, fundamentalmente, una lectura retórica de la monstruosidad, los casos del asinus-pontificius y el vitulomonachus, sobre los que disertan Lutero y Melanchthon, son, fundamentalmente, lecturas basadas en la colación de pasajes escriturarios que mencionan algunas de las particularidades que los dos autores creen encontrar en su objeto.

La utilidad de los catálogos de prodigios es, en cierto modo, la de aproximarse a la sistematización de estas manifiestaciones y signos divinos, y procurar también una historia de la pre-significación: esta historia permitiría, por acumulación de noticias, extraer algunos principios para su interpretación, y, sobre todo, establecer la correlación entre los hechos prodigiosos y los hechos históricos pre-anunciados por ellos. Indirectamente, por tanto, las crónicas prodigiosas permitirían realizar una descripción del código utilizado por Dios y corroborar, por acumulación, la tesis de que Dios ha jalonado la historia de signos. La interpretación de los monstruos y los prodigios, de hecho, acude, en ocasiones, a la secuencia de signo y hecho significado de prodigios anteriores para apoyarse en la regularidad de esta secuencia (si puede ser hallada) ante cada nuevo caso. Evidentemente, las bases analógicas de las interpretaciones permiten encontrar elementos invariables: a saber, los instaurados por los mismos criterios analógicos o trópicos de los intérpretes (por ejemplo, el cuerpo como Iglesia o Estado, el arma como guerra).

Sin embargo, es común la apreciación de lecturas «oportunistas», que contravienen la pretendida regularidad de manifestaciones. $O$, en otros términos, las relaciones analógicas pueden sustraerse a la regularidad de detalle según la intención del intérprete. Así, por ejemplo, la presencia de una sola cabeza en un cuerpo doble, en el caso del gallo de Alsacia, indica que la Iglesia reconoce una sola cabeza, Cristo, y no una doble cabeza (Cristo y el Papado): la presencia de otras cabezas únicas para cuerpos dobles no se lee necesariamente, como cabría esperarse, en el mismo sentido, sino que puede variar según los casos (la apariencia general del monstruo, el lugar de aparición, la intención 
semántica y propagandística del intérprete). Tampoco la aparición de cabezas dobles se lee, a contrario, como un reconocimiento de la autoridad papal, como parecería seguirse de la interpretación del pollo doble de Alsacia. En cada momento, la dirección de la propaganda determina, en gran medida, la forma de lectura del significante analógico.

Baste un solo ejemplo de esta variabilidad de la lectura de detalle sobre la base común de algunas analogías fundamentales: en 1547 nacen siameses en Lovaina. Están unidos por la espalda, y tienen duplicadas la cabeza y todas las extremidades, así como una buena parte del tronco. Lycosthenes ilustra el prodigio con una representación de los siameses, cuyas cabezas miran en direcciones opuestas. Peucerus, en la Teratoscopia y Fincelius, en su catálogo prodigioso, interpretan el hecho como una representación de la teología de los universitarios lovanienses católicos, responsables de la producción de un índice expurgatorio: la doble cabeza indica la monstruosidad de su doble lealtad a la tradición y la ley, por una parte, y a las escrituras, por otra: estas dos cosas son radicalmente opuestas, como demuestra el hecho de que las cabezas de los siameses se opongan entre sí. La teología lovaniense es monstruosa: tiene una doble cabeza irreconciliable, pues una cabeza no conoce la otra. Podrían aducirse otros casos semejantes: las cabezas únicas de monstruos múltiples pueden indicar el respaldo de todos los príncipes al Emperador, o la unidad de todas las partes del Estado, o la deseable unidad de los fieles en una única confesión. En general, todas las lecturas mantienen un núcleo común: la cabeza equivale, generalmente, a la autoridad (civil o religiosa) o a la instancia última de poder (el Emperador, el Papa), o a los principios rectores y «capitales» (principios teológicos, principios políticos). $\mathrm{Su}$ lectura está unida, en cada caso, a la lectura de la totalidad del cuerpo (como Estado o Iglesia, generalmente). Sobre esta base analógica común, sin embargo, se producen variaciones múltiples que dependen de muchas instancias.

\section{MONSTRUOSIDAD Y PROPAGANDA}

La interpretación de los monstruos se justifica como un comentario o una glosa del lenguaje de la divinidad. Es evidente que estas interpretaciones en las crónicas y las teratoscopias, tienen una función pro- 
pagandística de las tesis de la Reforma. De hecho, hay una breve serie de monstruos «clericales» que sólo pueden justificarse cabalmente en el contexto de propaganda política y religiosa de la primera mitad del siglo XVI. Los casos más conocidos, que ya ha habido ocasión de mencionar aquí, fueron los de los dos monstruos descritos e interpretados por Lutero y Melanchthon en 1523: el primero de ellos era un ternero nacido en Freiberg, en Sajonia, el 8 de diciembre de 1522; el segundo era un monstruo fabuloso presuntamente hallado en el Tíber, en Roma, en 1496, cuando bajaron las aguas tras una crecida del río. La deformidad del ternero monstruoso -en las orejas, la lengua, el pecho-parece remedar la figura de un monje en las ilustraciones más difundidas; el animal hallado en el Tíber es el resultado de la composición de muchos otros (cabeza de asno, pata de elefante, senos de mujer, escamas de pescado, etc.).

Melanchthon y Lutero entienden que tales monstruos son signos y proceden a la interpretación del conjunto del animal y de cada una de sus características, y avalan su lectura mediante los pasajes escriturarios correspondientes. En el plano general, ambos tienen por evidente que Dios ha propuesto a los hombres que contemplen el papado y al monacato como monstruosos (ya que el asno ha sido hallado en Roma y el ternero parece un monje); en el particular, cada una de las características monstruosas de los dos animales son, a su vez, significativas, y esos significados sólo pueden ser aprehendidos mediante una lectura alegórica y analógica. A imitación del vitulomonachus y del asinus pontificius, comparecen, en los años siguientes, monstruos que responden a una intención propagandística obvia, como el pez-obispo (cuya cabeza parece una mitra), el pez-monje (cuyo cuerpo parece reproducir un hábito monacal) o el más infamante porcosacerdos (el cerdo cuya cabeza parece lucir una tonsura). En estos casos, la práctica de considerar los monstruos y prodigios como signos ha inducido la reelaboración de sátiras teriomórficas de contenido claramente religioso. En general, puede afirmarse que una gran parte de los prodigios de los tiempos recientes, esto es, de los posteriores al 1500, aluden a la reforma, la profetizan ex eventu, o se acumulan en fechas relevantes del enfrentamiento de Lutero o los reformistas y el papado (1517, 1521, 1547), bien porque Dios se manifieste para apoyar las doctrinas reformistas o para descalificar a la Iglesia de Roma, bien porque pre-signifique de este modo los hechos más importantes para la nueva Iglesia reformada. Así, por ejemplo, la prisión del Elector de Sajonia por Carlos $\mathrm{V}$ y la derrota protestante de 1547 están precedidas por lluvias de cruces que se fijan indeleblemente en las vestiduras de los hombres, 
por la aparición de cielos teñidos de sangre en la región de Sajonia, por lluvias de clavos y coronas de espinas, por visiones complejas en los cielos, muy elaboradas, que permiten una interpretación à clef. Esto es, no sólo la interpretación, sino también la distribución de los prodigios sirve a la causa reformista.

Pero la Reforma no hace más que actualizar, multiplicar y extremar un procedimiento de lectura que posee una venerable antigüedad. Los precedentes inmediatos pueden indagarse en la práctica propagandística de Maximiliano II, o de los intelectuales comisionados con ese fin, que auspició la difusión de panfletos impresos destinados a la interpretación política de la monstruosidad y el prodigio: buena muestra de ello son los cerdos dobles que fueron objeto de poemas latinos y vernaculares de Sebastian Brant y las tareas «literarias» de Grünpeck en la Auslegung y el Speculum. En todos los casos, los monstruos tienen lecturas alegóricas y retóricas destinadas a ganar la adhesión de los lectores para las causas defendidas por Maximiliano. Ahora bien, estos precedentes recentiores lo son en tanto que un modo de lectura de venerable antigüedad está al servicio de causas políticas, es un instrumento de propaganda, se sirve de la imprenta, del libellus y de la pagella - del panfleto y el pliego suelto- para aumentar su difusión y acompaña el texto de una ilustración vívida y poderosa. El método de interpretación, en cambio, tiene antecedentes grecolatinos en textos de Obsequens, Livio, Plutarco y de la tradición paradoxográfica.

\section{APOCALIPSIS: LA INTERPRETACIÓN ESCATOLÓGICA DEL PRODIGIO Y EL MONSTRUO}

La interpretación apocalítica de los monstruos y prodigios es extremadamente común en los libros germánicos. Por una parte, es evidente que cada monstruo o prodigio particular es un signo que predice sucesos precisos y con un valor alegórico y doctrinal específico. Por otra parte, sin embargo, todo prodigio o monstruosidad puede ser interpretado como un indicio de la proximidad del fin del mundo. En este sentido, cada monstruo o prodigio no es únicamente un signo o una praesensio, sino que todos ellos, en conjunto, o, más exactamente, su acumulación y frecuencia, son un indicio cierto de un único hecho ulterior. Los prodigiastri establecen una relación entre la proliferación de prodigios en estos tiempos de impiedad y la segunda venida de Cristo que se sustenta sobre evidencias escriturarias: tanto los discursos 
escatológicos de los evangelios (Marcos, 13; el «pequeño apocalipsis» de Mateo, 24; Lucas 21) como los libros de los profetas afirman que el fin del mundo estará precedido por signos y portentos en los cielos y en la tierra, así como por el nacimiento de monstruos. Uno de los pasajes aducidos más frecuentemente por los prodigiastri procede del libro de Joel (Joel, 2: 28-31), en el que puede leerse que, antes del día terrible del Señor, los hijos y las hijas profetizarán, los viejos tendrán sueños y los jóvenes, visiones, y Dios manifestará sus prodigios y maravillas en los cielos y en la tierra, con fuego, sangre y columnas de humo y el sol se oscurecerá y la luna se ensangrentará. Este pasaje se reveló especialmente significativo en los escritos reformistas: justifica la predicación de los laicos en la plaza pública y a través de panfletos religiosos, y establece una relación evidente entre la proliferación de profecías y el fin del mundo. La lectura apocalíptica de la monstruosidad, como algunas de las lecturas alegóricas, está basada en la evidencia escrituraria: sin embargo, la praesensio o la presignificación del prodigio es en este caso genérica, pues cualquiera que fuere el prodigio manifestado, todos ellos anuncian la proximidad del fin.

Una de las características más notables de los catálogos de portentos es que todos ellos enfatizan el número creciente de prodigios que se producen en los tiempos modernos: de hecho, tanto en las crónicas de Lycosthenes como en las de Frytschius y Fincelius, los ocurridos después de 1500 superan en número y horror a todos los ocurridos antes de esa fecha en la historia del mundo. Por ello, afirman su convicción de vivir en una edad prodigiosa, en una mutatio jalonada por signos divinos, en el momento de desorden que precede el dies novissimus y el fin de los tiempos. La proliferación de prodigios es un indicio cierto de la decrepitud del mundo y de la confusión de la naturaleza, pues se presume que, en los tiempos seniles, los hombres presenciarán atónitos la confusión y el desorden. El tópos del mundus senescens tiene una presencia notabilísima en las crónicas de la presignificación y en los tratados de teratoscopia, y comparece también en la historiografía, en los tratados cronográficos y en los textos de materia escatológica. No obstante, debe señalarse que la expectación del fin no se sostiene únicamente sobre la acumulación de prodigios, sino que es también el resultado de la exégesis escrituraria, de la especulación cronográfica sobre las edades del mundo, de la lectura figurativa de las armonías de los tiempos y, sobre todo, es el producto de una concepción degenerativa de la historia basada, fundamentalmente, en el libro de Daniel. En este sentido, los prodigios aportan una evidencia suplementaria que corrobora nociones sobre la historia, la cronología y la progresión de los tiempos. 


\section{Referencias bibliográficas}

Aldrovandus, Ulysses (1642). Monstrorum Historia cum Paralipomenis Historiae Omnium Animalium. Bononiae: Nicolae Tebaldini.

BAUHINUS, ANDREA (1614). De hermaphroditorum monstrosorumque partuum natura. Oppenheimii: Typis Hieronymi Galleri.

BoAistuau, PIERRE (1560). Histoires prodigieuses, les plus memorables que ayent esté observees, depuis la Nativité de Jesus Christ jusques à nostre siecle. Paris: Vincent Sertenas.

BRANT, SEBASTIAN (1915). Einblattdrücken, Heitz.

FINCELIUS, JOBUS (1556). Wunderzeiche, Warhafftige Beschreybung und gründlich verzeichnuss schröcklicher Wunderzeichen und Geschichten. Jhena: Rödinger.

- (1559). Wunderzeiche, Warhafftige Beschreybung und gründlich verzeichnuss schröcklicher Wunderzeichen und Geschichten. Leipzig: J. Berwald.

- (1562). Wunderzeiche, Warhafftige Beschreybung und gründlich verzeichnuss schröcklicher Wunderzeichen und Geschichten. Jhena: Richtzenhan.

FRYTSCHIUS, MARCUS (1555). Catalogum prodigiorum, miraculorum atque ostentorum. Noribergae: in officina Ioannis Montani \& Ulrici Neuber.

- (1563). Catalogum prodigiorum, miraculorum atque ostentorum. Noribergae: in officina Ioannis Montani \& Ulrici Neuber.

Goltwurm, CASPARUS (1557). Wunderwerk und Wunderzeichen Buch. Francofurti ad Moenum: David Zöpfel.

GRÜNPECK, JOSEPH (1507). Eine neue Auslegung der seltsamen Wunderzeichen. Nürnberg: Johann Weissenburger.

- (1508). Speculum naturalis coelestis \& propheticae visionis: omnium calamitatum tribulationum \& anxietatum: quae super omnes status: stirpes \& nationes christianae reipublicae: praesertim quae cancro \& septimo climati subiectae sunt: proximis temporibus venturae sunt. Nurenberge: Georgius Stuchs.

IrenaEUS, M. Christophorus (1584). De Monstris. Von seltzamen Wundergeburten. s. 1.

JONSTONIUS, JOHANNES (1632). Thaumatographia Naturalis in 10 classes distincta. Amstelodami: apud Guilielmum Blaeu.

LANDRAY, JEAN (1603). Teratologie ou Discours des signes et prodiges. Clermont: Bertrand Durand.

LICETUS, FORTUNIUS (1616). De monstrorum caussis, natura \& differentiis libri duo. Patavii: apud Casparem Crivellarium.

LUTHERUS, MARTINUS (1523). Deuttung der grewlichen figur des Munchkalbs zu Freyberg in Meyssen gefunden. Erfurt: Wolfgang Stürmer.

Lutherus, Martinus \& Melanchthon, Philippus (1523). Deüttung der czwo grewlichen Figuren Bapstsesel czu Rom und Munchkalbs czu Freyberg ijnn Meysszen funden. Wittenberg: Grunenberg.

Lycosthenes, ConRAdus (1557). Prodigiorum ac Ostentorum Chronicon, quae praeter naturae ordinem, motum et operationem, et in superioribus \& his inferioribus mundi regionibus, ab exordio mundi usque ad haec nostra tempora, acciderunt. Quod portentorum genus non temere evenire solet, sed 
humani genere exhibitum, severitatem iramque Dei adversus scelera, atque magnas in mundo vicissitudines portendit... Basileae: H. Petri.

Melanchthon, Philippus (1523). Deuttung der grewlichen Figur des Baptsesels zu Rom in der Tiber gefunden. Erfurtm: Wolfgang Stürmer.

- Vid. quoque: Lutherus, Martinus.

OBSEQUENS, IULIUS (1551). Prodigiorum Liber Imperfectus. Lugduni: apud Seb. Gryphium.

- (1552). Prodigiorum Liber, ab urbe condita usque ad Augustum Caesarem, cuius tantum extabat fragmentum, nunc demum historiarum beneficio, per Conradum Lycosthenem Rubeaquensem, integrati sunt restitutus. Basileae: Oporinus.

PARÉ, AMBroise (1971). Des monstres et prodiges [(1561)]. Génève: Droz.

PeUCERus, Casparus (1553). Commentarius de praecipuis divinationum generibus in qua a prophetiis divina autoritate traditis, et Physicis praedictionibus, separantur Diabolicae fraudes et superstitiosae observationes, et explicantur fontes ac causae Physicarum praedictionum, Diabolicae et superstitiosae confutata damnatur. Witebergae: Johannes Cratus.

SCHENCKIUS, JOHANNES GEORGIUS (1609). Monstrorum Historia Memorabilis. Francofurti.

SORBINUS, ARNALDUS (1570). Tractatus de Monstris quae a temporibus Constantini huiusque ortum habuerunt, ac iis, quae circa eorum tempora acciderunt, ex Historiarum cum Graecarum tum Latinarum testimoniis. Parisiis: apud $H$. Marnef et $\mathrm{G}$. Cavellat.

WEINRICHIUS, MARTINUS (1595). De ortu monstrorum commentarius. Sumptibus Henrici Osthusii. 